July - 2005

\title{
Navigating Distance and Traditional Higher Education: Online faculty experiences
}

\author{
Alice G. Yick, Pam Patrick and Amanda Costin \\ Capella University \\ USA
}

\begin{abstract}
The academic culture of higher educational institutions is characterized by specific pedagogical philosophies, assumptions about rewards and incentives, and values about how teaching is delivered. In many academic settings, however, the field of distance education has been viewed as holding marginal status. Consequently, the goal of this qualitative study was to explore faculty members' experiences in a distance education, online university while simultaneously navigating within a traditional environment of higher education. A total of 28 faculty members participated in a threaded, asynchronous discussion board that resembled a focus group. Participants discussed perceptions about online teaching, working in an institution without a traditional tenure system, and the role of research in distance education. Findings indicated that online teaching is still regarded as less credible; however, participants also noted how this perception is gradually changing. Several benchmarks of legitimacy were identified for online universities to adopt in order to be viewed as credible. The issue of tenure still remains highly debated, although some faculty felt that tenure will be less crucial in the future. Finally, recommendations regarding attitudinal shifts within academic circles are described with particular attention to professional practice, program development, and policy decision-making in academia.
\end{abstract}

Keywords: distance education; online education; online faculty experiences; academia; tenure

\section{Introduction}

Advancements in technology have expanded the traditional boundaries of education beyond the brick-and-mortar university or college on a land-based campus. Institutions realize online learning is a market demand. The Sloan Consortium found that during Fall, 2002, 1.6 million students took an online course (Allen and Seaman, 2003). More than three-quarters of all higher education institutions offer at least one online course; and recognizing that the demand will only increase, 67 percent stated that it remains in their future strategic planning (Allen and Seaman, 2003). In spite of the prevalence of online course offerings, many faculty members are still ambivalent about online teaching. They may have accepted the value and legitimacy of online learning, yet not all have embraced this new technological delivery system. This is consistent with other studies that indicate that faculty in traditional institutions are not enthusiastic about participating in distance education (Olcott and Wright, 1995). Distance education still holds a marginal status within a traditional institutional reward system based on tenure and advancing in faculty rank (Wolcott, 1997). 
Most research studies have focused on faculty employed at land-based campuses and who teach online courses as part of their academic workload. Satisfaction among adjunct faculty teaching online (i.e., Fredericksen, Pickett, Shea, Pelz, and Swan, 2000; Hartman, Dziuban, and Moskal, 2000) and faculty attitudes toward online teaching (Jones, Lindner, Murphy, and Dooley, 2002; Redline, 2001) have been examined. An extant literature search showed that there are minimal studies about the experiences of faculty members from online universities - with the exception of Ryan, Carlton and Ali's (2004) study about nursing faculty experiences in teaching, communicating with learners, and new pedagogies in distance learning institutions. As online teaching becomes more entrenched, we will witness more studies about the experiences and social perceptions of faculty members in online universities, particularly their experiences as they navigate in an academic climate that is influenced by the values and norms of traditional brickand-mortar institutions.

This qualitative study gave "voice" to faculty members who have chosen to teach at Capella University, an accredited, for-profit online university. For example, how do their colleagues in traditional institutions perceive their role as online faculty teaching at an online university? Would teaching at an online university adversely affect their opportunities to teaching at a traditional university? What are some of the issues raised about the credibility of distance education? After extrapolating the themes related to these online faculty members' perceptions and experiences, specific practice, program, and policy recommendations will be offered within the context of higher education. Such recommendations are particularly valuable in light of fact that technology continues to rapidly evolve as a means of delivering education and as traditional campuses are moving to incorporate online instruction with traditional face-to-face teaching.

In this article, distance education is a general term referring to:

Planned learning that normally occurs in a different place from teaching and as a result requires special techniques of course design, special instructional techniques, methods of communication by electronic and other technology, as well as special organizational and administrative arrangements (Moore, 1996, Para. 1).

Online distance education refers to curricula delivered solely through the Internet. It does not include blended courses, which encompass both face-to-face interactions and technology. Asynchronous discussions consist of text-based communications carried out on a non-real-time basis that spans different times and locations. Online faculty members are affiliated with an institution that delivers curricula solely through the Internet, while traditional faculty refers to those who teach in a physical classroom on a land-based campus. The term "faculty" will be used primarily to mean instructors who facilitate the online course room, although in distance education, the terms "tutor" and "mentor" have been substituted to reflect the pedagogical philosophy of shifting from teaching to learning (Rogers, 2000). Similarly, the term "learner" refers to students and is used in place of the term "student" reflecting again the philosophy learning-centeredness in distance education.

\section{Literature Review}

To understand the social realities and experiences of online faculty members, we have to recognize the interplay of factors, including prevailing attitudes among faculty and administrators about distance education, and the current and historical climate and philosophy about distance education. This is embedded within a culture of institutional values and assumptions, as well as a traditional tenure/ reward system found in higher education. 


\section{Pedagogy of distance education}

The pedagogy of online learning is in contrast with that in brick-and-mortar institutions. Online teaching revolves around the learner, shifting being teacher-centered to learner-centered, which emphasizes that learners possess a wealth of knowledge where the teacher is not the only repository of information (Markel, 1999). The term "mentor" is applied to the faculty to capture the flavor of the new relationship between learner and teacher - more collaborative and less hierarchical (Markel, 1999). The new role of the faculty is to facilitate learning (Beaudoin, 1990).

Faculty perceptions toward distance education are mixed at best. Overall, faculty members appear reluctant to participate in distance education (Olcott and Wright, 1995). There is a perceptual disparity in academia that distance education is second best (Giannoni and Tesone, 2003). Others voice concern about the ability to reliably track learner's progress at a distance (Folkers, 2005). Other faculty wonder about any changes to already busy faculty workloads since distance education is time consuming (Ellis, 2000). Questions about the rewards associated with adopting distance education as part of the faculty teaching repertoire also are of concern (Folkers, 2005). It is possible that as distance education becomes more embedded in the culture of higher education, faculty perceptions will change? In a more recent large scale survey study by Berge (2002), employees in corporate settings who use distance technology for training, perceived barriers is also a function of the level of perceived maturity of the organization in using distance education. In other words, different perceived barriers exist during different stages of the implementation and maturation of technology within an organizational context. For example, the barriers of technical difficulties and support and organization culture and change become less burdensome when distance education becomes institutionalized or integrated in an educational institution's delivery structure.

\section{Infrastructure of distance education and unbundling faculty functions}

The infrastructure of distance education shifts from a campus-centric model to a consumer-centric model since learners become less reliant on an academic infrastructure based on human mediation. With distance education, learners now can obtain services more quickly through automated systems (Beaudoin, 1998). Ultimately, options increase for learners, and this transitions them to the role of consumers. Therefore, curricula must reflect learners' needs, and learners determine the location for learning, the time when they want to learn, and the pace of learning (Evans and Fan, 2002).

Since it was first introduced in the mid-1970s, the concept of unbundling faculty roles has resurfaced. Unbundling refers to the process of assigning costs associated with delivering distinct components of instruction (Paulson, 2002). Typically, in traditional institutions, faculty teach, conduct research, advise, and perform service within the parameters of a physical setting dedicated to those purposes. The faculty member develops and teaches the instructional units, thereby reflecting one individual's intellect (Sumler, 2004). In distance education, however, "unbundling" breaks up these activities, and each activity is assigned to a number of professionals including instructional designers, adjunct faculty, and technologists (Academic Leader, 2004).

\section{Institutional culture of rewards}

The reward structure in distance education environments is also distinctly different. Traditionally, tenure is one of the ways faculty members are rewarded. It is estimated that 90 percent of all fouryear higher education institutions and 99 percent of public universities in the United States have a tenure track system (Brown, 1999). Tenure was originally designed in the early $20^{\text {th }}$ century to 
protect professors who teach and write about controversial topics from fear of losing their positions (Chronicle of Higher Education, 2000; Lataif, 1998). It is based upon Western values promoting free inquiry, with the notion that if empirical inquiry was in any way constrained, then society will stagnate (Tierney, 1998). Many argue, however, that tenure provides lifetime employment without promoting quality work (No Author, 2000) and can discourage faculty experimentation with new technologies. The risk that this poses to the institution is that junior faculty who are not yet tenured will only want to devote themselves to activities leading to tenure.

Perceived institutional priorities traditionally shape faculty behaviors. Despite the expectation that teaching, research, and service are equally emphasized, faculty working in research universities perceive research and scholarship as highly valued (Wolcott, 1997). Although many administrators and faculty acknowledge that standards for tenure are often nebulous and will often times produce unhappy and anxious faculty, the universal goal is to obtain tenure (No Author, 2000). It is within this climate that we can better understand faculty members' attitudes toward distance education and the use of innovative technologies in delivering education.

Wolcott (1997) looked at faculty reward systems and how distance teaching is valued and rewarded within a culture of tenure. What Wolcott found was that the institutional reward system shapes decisions about participation in distance education activities. Faculty and administrators do not attach the same amount of prestige to distance education as with other activities such as research and scholarship. Wolcott found that many promotion and tenure documents do not mention distance education as activities for which faculty should receive "credit" toward achieving tenure. When distance education is counted, it is merely credited as teaching despite the contention that it involves greater time commitment and work. When counted as service, it is weighted less toward promotion and tenure (Wolcott, 1997).

These concerns are also reflected in Wolcott and Bett's (1999) qualitative study with 32 faculty members. Many noted that teaching via distance education involves much "hidden" work such as helping learners adapt to new technologies and creating extensive amounts of course materials, academic activities not recognized by tenure decision makers. Participants wrestled with viewing distance education as part of the teaching load or whether it should be treated as an overload i.e., treated as "above and beyond" a regular teaching assignment. Those who decide to participate in distance education do so because they desire to grow professionally, and they recognize it fits within their professional values. This same issue of workload and time investment was noted in Rockwell, Schauer, Fritz, and Marx's (2000) qualitative interviews with administrators. Faculty were concerned about not receiving credit for incorporating distance education into the teaching workload.

Ellis' (2000) qualitative study explored the challenges encountered when full-time faculty members at the Pennsylvania State University World Campus, a large public institution, taught distance education courses. The majority of administrators and faculty indicated that release time is the major barrier to faculty participation in distance education. Release time is needed so that faculty can replace teaching on-campus courses with developing and/ or teaching distance education courses. Again, the time factor would detract from activities that affect promotion and tenure.

Traditional ways of managing the academic process cannot be directly applied to distance education institutions, such as online universities. As the for-profit sector increases its participation in distance education, it has not adopted traditional academia's taken-for-granted assumptions about tenure, administrative infrastructures, faculty roles, and pedagogy. Online faculty members' experiences therefore are influenced by both the climate in distance education as well as traditional institutions. 


\section{Methodology}

\section{Research design and context}

This study utilized a qualitative research design, specifically, an asynchronous online threaded discussion board focus group. The use of discussion boards as virtual focus groups has become increasingly popular (Moloney, Dietrick, Strickland, and Myerburg, 2003). Virtual focus groups enhance participation because of convenience, particularly for this study where faculty participants were geographically dispersed.

The study was conducted with online faculty, including both core faculty (full-time) and adjunct faculty from the School of Human Services at Capella University. Capella University is a forprofit, accredited online university that offers strictly online courses. ${ }^{-}$. The School of Human Services is made up of diverse program areas: General Human Services; Criminal Justice; Healthcare Administration; Management of Non-Profit Agencies; Mental Health Counseling; Marital, Couple, and Family Counseling/ Therapy; Counseling Studies, and Social Work and Community Services. The university operates within a quarter system, in which learners take asynchronous online coursework to complete MS and PhD degrees. It does not adhere to the traditional tenure track system, and faculty performance is reviewed annually by the Program Area Chairs for each curriculum.

During the 2003 academic year when this study was conducted, there were 58 faculty members who were either adjunct or core faculty members in the School of Human Services. The majority $(n=43)$ were adjunct faculty, teaching two to four online courses a quarter on a part-time basis and advising a limited number of Masters and PhD learners. Adjunct faculty are often practitioners in their respective disciplines, and some also hold faculty appointments at traditional brick-and-mortar universities. There were 15 core faculty members, who are full-time and teach a maximum of two-to-three online courses a quarter, advise both Masters and $\mathrm{PhD}$ level learners, serve on committees, and perform other academic duties linked to the School of Human Services.

\section{Sampling Design and Profile of Sample}

A convenience sample was recruited from the faculty (minus the three researchers, all core faculty). An email was sent describing the study and soliciting participation, and the final sample consisted of 28 faculty members, representing 50 percent of the School of Human Services faculty. Slightly more adjunct faculty $(n=18)$ participated in the study than did core (full time faculty). The gender composition was evenly divided; however, there was noteworthy diversity in age, ranging from 31 to 69 years of age, with the average age of 51 years. Faculty represented diverse program areas; however, more participants received their terminal degree from a traditional university. All participants received their PhDs from regionally accredited institutions. Faculty participants were relatively new to the university, with the median time teaching at 1.5 years and a range of two months up to six years. The majority were practitioners and many worked as adjuncts in other traditional universities. Many participants had no previous online teaching experience. Table 1 summarizes the demographic and social profile of the sample. 
Table 1. Demographic Profile of Participants $(n=28)$

\begin{tabular}{|l|l|l|}
\hline & N & $\%$ \\
\hline Gender & 13 & \\
\hline $\begin{array}{l}\text { Male } \\
\text { Female }\end{array}$ & 15 & 46 \\
\hline Affiliation & 18 & 54 \\
\hline $\begin{array}{l}\text { Adjunct } \\
\text { Core }\end{array}$ & 10 & 64 \\
\hline Program Areas & 36 \\
\hline $\begin{array}{l}\text { Administration and Management* } \\
\text { Counselor Education** } \\
\text { Social Services**** }\end{array}$ & 7 & 25 \\
\hline $\begin{array}{l}\text { Type of Institution of Terminal Degree } \\
\text { Traditional University } \\
\text { Non-Traditional University }\end{array}$ & 11 & 39 \\
\hline $\begin{array}{l}\text { Previous Online Teaching Experience } \\
\text { Yes } \\
\text { No }\end{array}$ & 19 & 36 \\
\hline
\end{tabular}

*Adminitration and Management conprises of both Health Care Adminitration and Mamagement of Hon-Profit Agencies)

**Counsebr Education consits Mental Health Conmseling and Marital, Couple, and Family Conmseling/ Therapy

*:*kSocial Services inchude Crimmal hustioe, and SocialWork and Commonity Servioes

\section{Data Collection and Analysis}

The study was approved by the university's Institutional Review Board. An online discussion board was set up and was active for a three-week period, and the three researchers took turns facilitating it. Each week, new discussion questions were posted, and all participants were encouraged to dialogue with one another, with the researchers moderating and facilitating the discussion. All participants were encouraged to revisit the previous week's discussion in order to continue conversations started during that period. The following questions were posted for faculty discussion:

1) How do you think your colleagues in traditional academia perceive your work teaching for an online university?

2) Do you think your work with an online University would help or hinder you if you decided to teach on the tenure track at a traditional university? Why or why not?

The following questions were posted as a result of recurrent discussion in the area of tenure and the role of research:

3) What types of reactions have you received about Capella University not having a "tenure" track?

4) What do you think faculty can do to begin building this research focus? 
At the end of the study, participants completed a close-ended survey that consisted of demographic questions. All the discussion postings were downloaded, and content analysis was conducted to extrapolate recurrent themes.

\section{Findings}

\section{Perceptions of online teaching}

Participants were asked what their colleagues from traditional brick and mortar institutions thought about their teaching at an online university. Reactions were mixed. Negative reactions directed towards distance education still exist seemingly based on the notion that distance education is not credible or equivalent to traditional classroom education. As one faculty participant stated, it is a quality control issue since some traditional faculty still perceive that online education is "diluting the quality of higher education.”

For faculty not involved in this style of learning, many still do not believe it has equal value. (E.R.)

My tradition-bound colleagues do not believe that the online university can 'do the job.' (K.Z.)

During this discussion about the perceived lack of credibility, one of the researchers posted: "Where is it ('the less credibility') coming from? What makes it 'less credible'?" Participants felt that much of the criticisms about distance education stemmed from lack of understanding, knowledge, and information about distance education - all of which can elicit fear. Without adequate knowledge, it is easy to attribute and perpetuate negative stereotypes about distance education. It is not easy, however, to completely understand the impact of online teaching until a faculty member actually employs the technology and then becomes a "convert."

I think there is a fear factor involved - people criticizing that which they do not understand. For example, remember when University of Phoenix, National, Chapman, and many of the other night MBA programs began? They were deemed to be 'less serious (read less rigorous) programs, and therefore, the degrees were considered to be somehow not as good as those from a big name university with a traditional program. Now those degrees are respected (for the most part). (S.T.)

It has been my experience that those who think this way have not really taken the time to look at all the types of online instruction. Rather these people have seen the worst of the courses and then equate online delivery with correspondence school material. The only converts that I have run into are those who have been forced to teach/ create a class. When one finds how well the students perform (the knowledge that is gained) s/he becomes a convert (R.A).

Furthermore, a sense of elitism pervades many traditional institutions, and ultimately, many faculty fear that technology will precipitate change - change that might affect their jobs. One participant noted with wry amusement about his colleagues' initial reactions about him working in an online university and how this changed when they had to teach an online course.

Initially [my] colleagues who taught at traditional university were surprised and horrified. . . However, as their universities introduced a few online courses . . . 
hence they would phone me in panic, asking for advice and tips. Their initial responses, from my perspective, amounted to a lack of information and academic 'elitism.' (D.V.)

Finally, distance education still evokes images that harkens back to the "early days correspondence courses and the sheepskin in the mail” (S.T.). It is crucial to contextualize such negative reactions, however. One faculty normalized such negative reactions as being commonplace since technology often challenges the status quo, bringing about anxiety and fear. He noted: “ . . . the university where I received my $\mathrm{PhD}$, there has been much resistance to online teaching by faculty members in my department . . . they are most afraid of what will happen to them in terms of their status. Change is sometimes painful."

Technology is never static - it is continually improves, making it more friendly for users. Consequently, prevailing myths and negative attitudes may be shifting as the overall climate and landscape of distance education has begun to change. There also may be something to be said about "safety in numbers." As more traditional, land-based universities adopt technology for the delivery of instruction, online courses are becoming more commonplace. "Commonplace" seems to connote normality and acceptability.

Two or three years ago, they thought that a distance learning education was Mickey Mouse. Today they are envious and trying to jump in . . . It is interesting that most of the brick and mortar institutions that are now also offering distance learning opportunities for their students and are making online teaching experience a requirement for faculty vacancies. (F.Y.)

My experience has been that faculty working in traditional settings, along with teaching online, are much more open to distance learning. Many traditional schools now offer distance learning programs/ degrees and see the potential in the adult learning market . . . An interesting development is the use of Blackboard in the traditional classrooms basically utilizing the same functions as an online course. (E.R.)

Witness the many universities that are now part of Sloan-C conferences - they realize that they need to offer at least some of their programs online in order to remain competitive. (S.T.)

Over time, participants have observed that their colleagues' interests are piqued, and many want to "get their foot in the door" of online teaching. Like the above faculty who noted how some colleagues are asking him for advice, others see similar changes in attitudes.

Many have been referred to Capella to become faculty because of the intrigue of online teaching. There is something charmingly engaging and enigmatic about being a faculty in an online university. (B.Z.)

Recently, in the last year or so, the spirit of the inquiries have changed to a different tone when asked 'So how does this work?' to 'Hey, can you put in a good word for me, I'd like to try it. (L.A.)

\section{Measures of credibility and role of research in distance education}

Three major "measures" of credibility or legitimization emerged from the data generated by the asynchronous focus group: 1) large student enrollment numbers; 2) accreditation; and 3) 
scholarship/ research. First, size counts. Large student enrollment numbers give an aura of credibility to the university. One participant commented: "I taught at X university for many years. The status of bricks-and-mortar with a large enrollment in a city like XXX and satellite campuses adds credibility to the programs." Second, recognized and accepted regional accreditation legitimizes programs and the University. It is a stamp of credibility that is understood by other institutions, academicians, and the general public. Several months prior during this research study, Capella University received news that their Mental Health Counseling program received CACREP (Council on Accreditation of Counseling and Related Educational Programs) accreditation. One faculty participant asserted that "accreditation has gone a long way to improve [our] image.” More work on accrediting other program areas is vital, however.

Third, the scholarship of faculty and learners also lends public credibility to the institution. Scholarship encompasses conducting research and the ensuing publications that would follow, bringing recognition to faculty and learners.

In the circles in which I travel . . it is expected that all are competent teachers . . . In most instances the thing that is used to separate folks in the credibility ladder is research based publications ... What I am saying is that it will not matter if one teaches at an online school or a traditional one, professionally, the researchers are given more credibility in the field. Again the view is that the role of the faculty is not simply a teacher in a Ph.D. program, but a generator of new knowledge. (G.R.)

The faculty were actively encouraged (even as adjuncts) to publish and present, and when they did (which they did often) it was highly publicized, including the link to University Y. In addition, students were actively encouraged to publish course papers that were great and the university helped find a home for a paper when the student was interested. Again the link to University Y was established and the public recognition added validation to the program. Despite our for-profit status, I think we need to establish a stronger link to research, including actively supporting faculty and learners in their possible endeavors. (S.T.)

As the topic moved into scholarship and research, participants were asked to expand on their thoughts regarding the role of research in an online university. Participants felt there are tremendous advantages to conducting research in a distance education institution, particularly one that specializes in online teaching. First, the resources in terms of talent are extensive and diverse. H.I. maintained:

Capella has the ability to bring in layers of talent from the country. For example, the process of course development involves a number of different layers of talented individuals . . . The same model could be employed to develop a pool of talented grant writers, research assistants, and others who would want to be part of the process.

Second, an online university that taps into populations, not necessarily reached by traditional universities, offers the opportunity for research that includes diverse samples because the learners themselves are from diverse geographic areas, ethnicities, and have diverse and rich life experiences. This also applies to faculty members.

Faculty living in various areas of the country can develop research proposals that take advantage of the geographical differences - urban/ rural, west/ east, Latino/ 
Anglo populations, etc. Making comparisons in this manner adds an important dimension to any project. (H.I.)

What classroom can you walk into that will have learners from a more culturally and ethnically diverse population than ours at Capella? Impossible. From these multi-diverse populations come comments and interactions that can only be generated from this type of environment. This diversity will definitely affect research efforts and outcomes. (Q.B.)

Finally, the opportunity for interdisciplinary and learner/ faculty collaboration is enhanced. Due to the range of program areas in the School of Human Services, scholarship can reflect this extensive and rich multidisciplinary setting. Learner/ faculty collaborations are strengthened because of the diverse interests of learners and faculty from a wide geographic area. Pooling resources through the use of technology can enhance research efforts.

Interdisciplinary cooperation can be promoted and effectively incorporated into research proposals if made a core value from the start. This can take place between schools as well within schools. I know that at brick and mortar institutions, cooperation between disciplines can be very difficult to foster. In my experience, such cooperation was the exception. (H.I.)

My experience tells me that some of the unique characteristics of Capella's virtual environment when compared to brick-and-mortar settings is that we are actively engaged with a wide variety of learners. The broader involvement should allow us to find learners with similar interests as ours and help us to collaborate with them to conduct further research. The same could probably be said of faculty collaboration. (Q.B.)

I agree that as a virtual faculty we encompass a great variety of backgrounds and similarly have a multi-culturally diverse student population available to sample in research efforts. Just as the research/ practitioner model has been popular in counseling practice, becoming oriented as faculty/ researchers is a mental set that needs to be developed. (L.A.)

All three participants above also reinforced the view that research should not be a tangential activity; rather a "core value" or "mental set" promoted by the university. Conducting research is essential for the faculty working with doctoral learners and for the faculty's professional growth.

I would see it as critical function of a faculty member in a doctoral program. As I have said many times in this set of discussions, the doctoral faculty member has a job of not only being a teacher but a generator of new knowledge. (G.R.)

Research is fundamental to my growth as an academician and a human being. I employ my sociological imagination to create a variety of research tasks, some may be published and some never see the light of day. The outcome is often less important the process. (H.I.)

The only concern noted about having a research focus in an online university was the creation of a "class system" where those who conduct research are more valued than those who just teach. One faculty expressed: "I suppose that I am more worried about a research emphasis creating a "class system" as it has in other schools. Others mentioned this last week, that the 'less than' perception focuses on research activities, or the lack of them.” (D.C.) 


\section{Tenure in distance education}

Participants were asked if their work in an online university would help or hinder them if they were later to decide to teach at a traditional institution with a tenure track system. The majority of the participants were not concerned about this issue and felt that their current work at an online university only enhances their options. It has given them experiences that other faculty members at traditional universities have often not acquired.

My full time position is at a traditional university. What I have learned and continue to learn at Capella only enhances my overall vita . . . This relationship has provided me with experiences other faculty members may not be exposed to. (E.R.)

I don't think being tenured would make any differences. The experience of teaching will be valued. (T.B.)

I already have experience working in a B\&M [bricks-and-mortar] university so this additional experience can only strengthen my position. (L.A.)

Because other universities are now adding a distance learning component, participants felt that their online teaching experiences would only serve as an asset.

The majority of tenure track institutions are including DL experience as either preferred or requisite for consideration for faculty vacancies. (F.Y.)

A definite factor in the past. Assume it is becoming less so every day as traditional universities implement their own nontraditional programs. (J.U.)

I do know that several non-tenured institutions are trying to get their courses online to meet the needs of the community. Experience teaching at an online university would be seen as an asset in this setting. (R.A.)

There were a couple of participants, however, who felt differently. For these faculty members, recognition that there currently is a lack of concerted research activity at online universities, combined with the fact that many traditional brick-and-mortar universities emphasize research activities in their tenure and promotion process, was viewed as holding the potential to hinder such a transition. G.R., for example, felt that his past teaching experience at a traditional university would help him make the transition back: "If I had no previous teaching/ research experience in traditional academia, I think it would seriously limit my chances if I did not have the previous experience.”

On the topic of tenure, the facilitator then posed: "Out of curiosity, what type of reactions have you received about Capella not having a tenure track?” Several participants felt that in the future, not having a tenure system will be a more prominent trend in higher education.

The only reactions I've ever had came from two colleagues at a former brickand-mortar school who believed that this was probably the wave of the future ... (H.I.)

Tenure is one of those concepts that I believe is increasingly outmoded. I have been at the receiving end of poorly done courses that have been taught by a tenured faculty member who has not updated materials or stayed current with 
new thinking in many years. And the university has not way to remove him/ her due to tenure. (S.T.)

If one does not have to offer it then why do it? I also am sure it is the wave of the future to not have tenure track positions. (G.R.)

A concern was expressed regarding not having a tenure system, however. Lack of such a system might stifle academic freedom.

... they all also express concern regarding being replaced if they have a different political or philosophical view than the administration and the potential for loss of academic freedom. (F.Y.)

Well, as a tenured faculty at a traditional university I do find the idea somewhat less desirable. What if I take an academic position that Capella finds it does not like? I have the academic freedom at my traditional university to call into question topics that are politically sensitive and not suffer any recriminations. . . (G.R.)

Finally, several participants expressed the viewpoint that tenure can affect quality of work and productivity in paradoxical ways: It can motivate faculty to higher productivity. G.R. observed: that "many schools are looking for ways to push teachers into being 'highly effective.' Tenure can, and often does, serve this role at most universities." However, it can have the opposite effect as noted by H.I. with respect to the "intractable problem of dead wood and dust collectors dragging down the quality of their department.”

\section{Discussion and Implications}

The finding of negative attitudes toward distance education, particularly to online learning, is not surprising. Vestiges of the notion that distance education are less rigorous and credible, and more inferior to traditional academia, remain. Society, however, has shifted to a knowledge-based economy that requires that individuals be taught numerous times using a variety of delivery methods. Lifelong learning has become the central tenet in education and training (Klor de Alva, 2000). This may not, however, necessarily translate into a change of attitudes among faculty employed at traditional land-based institutions. Change neither comes easily nor without resistance, and it frequently triggers uncertainties that ultimately evoke fears on a personal level. Folkers (2005) observed this resistance does not merely involve faculty's discomfort with using technology if they are unfamiliar with it; rather, distance education challenges current notions of power and control in higher education. Traditionally faculty have control over the content of the knowledge they distribute, but with distance education, faculty have to collaborate with other staff such as instructional designers over curricula, and administrators have greater scrutiny and supervision over the curricula (Folkers, 2005). Over time, and with the improvements of technology, our faculty participants have noted that distance education is receiving more attention and respect, which is inevitable given the increase of learners taking online courses and evident trends that traditional institutions are incorporating distance learning components (Sloan-CResources, 2005).

When viewing how attitudes toward technical innovation change over time, it is essential to recognize that application of technology in educational settings is a dynamic and changing process. Over time, technology improves and is enhanced, becoming more user-friendly. Consequently, prevailing myths and negative attitudes toward distance education will change as 
student enrollment increases in distance education and as more faculty members become more informed and comfortable in utilizing the technology. The literature has documented a pedagogical paradigm shift in education (Rogers, 2000) and, indeed, there is an intellectual acceptance of such a paradigm shift. Behavioral transitions, however, only begin when online instructors actually experience this delivery system and implement the new pedagogical philosophy of learning-centeredness. Meanwhile, their colleagues (some whom may be skeptical of online learning) are watching and listening to their experiences regarding how a computer mediated delivery system can be applied to teaching and learning, and how the role of the instructor is altered in the virtual environment. These "vicarious observations" of the hesitant or resistant faculty, where they observe the practices of colleagues who are teaching online, may be key to the process of changing negative attitudes toward distance education. Conversations about the online pedagogy and practice in this informal, collegial context can serve to reduce apprehension about online teaching in general and perhaps, serve to motivate faculty who are used to traditional face-to-face teaching to teach online. Reducing residual stigma about online distance education through this process is a softer, less threatening way to change attitudes about technology innovation in education. Ultimately, dissemination of information reduces fear of innovation although it may take a while for entrenched negative attitudes to completely dissipate.

Another key factor in this debate must be addressed: Online teaching is not suitable to all faculty members who wish to teach. While the pedagogy offers an option for teaching that is intriguing and engaging, these qualities may not be attractive to all campus-based instructors. Particular characteristics of an individual instructor (i.e., the art of teaching) may be more powerfully delivered by some in a face-to-face (FTF) format rather than an online format. Thus, the "best fit" argument is applicable to determining who will teach online and who will remain in the FTF setting. A central tenet of online distance education for learners is that it provides an educational option for those who otherwise would not have access to advanced degrees. The same holds true for the faculty member who wishes to teach, but for various reasons cannot do so from a campus setting.

In essence, there are three mechanisms that may aid in softening negative attitudes toward online teaching. First, administrative leadership in traditional settings may find that faculty resistance to online teaching reflects "best fit" considerations or that embarking on a new pedagogy is simply not appealing. It is essential in such circumstances that teaching assignments to online course development and teaching start with those faculty members who are intrigued and receptive. Based on this study's findings, the "bring along" effect may soften resistance; e.g., innovators receive the first assignments, obtaining appropriate training and support resources. As these pioneers experience success, other faculty may find the online teaching option more appealing.

Second, a faculty-to-faculty mentoring format holds the potential to provide collegial support for the first-time faculty venturing into online teaching. In this format, the experienced online instructor provides guidance and support to a colleague teaching his or her first online course. The mentoring process "transforms" the faculty through learning the specific and unique roles of the virtual instructor. Finally, a third option to soften resistance consists of team teaching. Using this option, administrators would assign two or three instructors to develop and teach their first online courses. Through shared experiences, the team of instructors can observe and learn from each other, encouraging each other to self-reflect about what works and what does not work. Central to the success of these strategies, however, is recognition that online teaching cannot be added on to a full workload of teaching FTF courses. Online teaching is intense, requires use of communication competencies that are different from those in a FTF setting, and therefore, administrative support and training are vital to ensure that these competencies are taught. This level of support ultimately paves the way to faculty success and satisfaction with the technology. 
It is important to remember that despite the emergence of many for-profit educational institutions and new paradigms of learning, traditional institutions will not disappear. They have longstanding traditions, which continue to shape public perceptions about credibility and legitimacy. Accreditation and research/ scholarship, for example, will continue to be the benchmarks of validity and legitimacy. More online universities are applying for accreditation, and accrediting bodies find themselves evaluating whether standards that were employed for brick-and-mortar institutions are appropriate for distance education institutions. Accrediting bodies will continue to evaluate quality control issues in regard to the online institutions' mission, faculty, students, curricula, instructional resources and scholarship (Vincent and Ross, 2002).

There is often less discussion about research and scholarship in distance education universities, particularly if they are for-profit institutions where research may be secondary (or absent) in their mission statements (Ruch, 2001). Yet, findings from this study point to the fact that research and scholarship are also the hallmarks to credibility for other academicians and to the outside world of academia, and therefore there is a need for further research within the School. Beyond symbols of legitimization, research and scholarship are still important to online faculty members since that is what they are trained to do and is the essence of who they are as scholars and educators (Ruch, 2001). It is also part of each faculty member's professional growth. For distance education institutions with a doctoral program to espouse to learners that they are to become scholar practitioners means that faculty, too, must model that role. In many ways, emphasis on research and scholarship remains consonant with the learning-centric model. In this study, participants identified the value of interdisciplinary learner/ faculty collaborations. Such collaboration fits in with Beaudoin's (1990) thought about distance learning pedagogy's emphasis on "what students do, not what teachers do"(p. 21).

It is plausible that conceptualisations of research and scholarship need to be reconfigured and redefined in an online environment. Although Edgerton (1993) was not directly addressing distance and online education, he talked about Eugene Rice, a scholar at the Carnegie Foundation, who proposed a reformulation of faculty's roles of not merely fulfilling the standard tasks for teaching, research and service, but of "advancing, synthesizing and integrating, applying, and representing knowledge through teaching” (Edgerton, 1993, p. 13).

Apparent in distance education, particularly in for profit institutions, is the lack of a tenure system. Many participants in our study were not concerned about making the transition back to traditional brick-and-mortar institutions and did not feel that their work at an institution without a tenure track system would impede them in any way. They felt their experiences are unique, and indeed, Ruch's (2001) informal interviews with online/ distance educators at several for-profit institutions found that they enjoyed the lack of pressure of tenure, which gave faculty the opportunity for greater academic freedom and creativity to shape instruction as well as shape academic culture. Yet, because of the notable lack of research and a tenure system at the University, academic publishing becomes a self-initiated activity. As a consequence, the reality is that scholarship is relegated to a lesser priority given the day-to-day demands of teaching and dealing with learner issues. Concerted administrative support and resources are needed to implement mechanisms whereby faculty members are encouraged to pursue and engage in scholarly activities. For example, in an online environment where faculty members are dispersed geographically, isolation from the day-to-day contact with virtual colleagues is typical. In the "distant" educational environment, what are the different levels of faculty support that is needed and is appropriate in order to pursue scholarly activity? One solution would involve administrative leadership and faculty exploring strategies to use the same technologies faculty use to communicate with learners (i.e., video conferencing, teleconferences, etc.) for faculty support groups; e.g., writing groups to promote scholarly writing and publishing. 
A discussion about tenure also brings up the issue of academic freedom. A couple of participants expressed the fear that without tenure, academic freedom would be hampered. Ruch's (2001) informal interviews found that academic freedom is now redefined in terms of freedom for innovation and creativity. Perhaps, in the shaping of a new academic culture, the definition of academic freedom will be expanded to include freedom in personal areas, which ultimately has positive influences on creativity. To be sure, administrators and chairs in online universities will need to incorporate new faculty development and ideas about sabbaticals to promote such academic freedoms. Will these "virtual" sabbaticals take the traditional form or will they be creatively defined in a different paradigm?

On the other hand, for some there is a concern that without tenure, productivity is decreased - i.e., a non-tenure system is a disincentive for academic activity. A counter to this argument focuses on a different set of "drivers" for performance: a stimulating, creative environment with a promising incentive structure and collegial spirit of innovation fostering high quality work (Ruch, 2001). Distance education and online universities, therefore, may have to reconceptualize new incentive structures to promote quality standards as well as encourage continued professional growth.

In general, there is the feeling that tenure is an outdated concept and that not having tenure track systems in higher education will be an increasing trend. According to Klor de Alva (2000), a 1998 poll of 50 state governors ("Transforming Post-Secondary Education for the $21{ }^{\text {st }}$ Century") found that there was a gap between the goals of traditional higher education and society. Specifically, the least important item judged was maintaining traditional faculty roles and tenure.

\section{Limitations of the Study and Directions for Future Research}

This research study represents a launching pad for more empirical work to be done in the area of remaking the academy, as described by Klor de Alva (2000). The process now impacting higher education has affected the perceptions and experiences of online faculty as they continue to navigate an academic culture that is influenced by norms of traditional institutions of higher education. This current research study was limited by a sample that represented only one school; specifically, the School of Human Services at the University. It would have been helpful to determine if similar experiences and realities are shared by other online core and adjunct faculty members throughout the other schools at the University (i.e., Psychology, Business, Technology, etc.) who may have different cultures and core values associated with their professional disciplines. A sample comprised solely of online faculty members is also biased or skewed, since information obtained about perceptions are from faculty who have made professional decisions to seek opportunities to use a new delivery system for education. A study comprised of both online faculty and faculty from traditional land-based institutions who use only face-to-face instruction could have yielded rich data comparing and contrasting their perceptions about distance and online education and tenure.

Future research studies need to continue exploring the dynamics of the seemingly volatile issues that technology can bring in higher education; that is, the interaction of how technology challenges traditional notions of how knowledge is disseminated, who owns knowledge, power struggles over limited resources, and the reconfiguration of previously entrenched structures (Shedletsky and Aitken, 2001). Where specifically in higher education do issues of cognitive dissonance exist that seemly exacerbate the difficulties with online and traditional instruction? How can both delivery systems function alongside, complementing each other's strengths and limitations? How can a "bring along" effect be used strategically by higher education institutions to increase faculty comfort levels using the collaborative strategies discussed? These and other issues represent rich areas for further investigation. 
The role of research and scholarship in online academia need to be explored in greater depth. Already scholars are debating the validity of online scholarship; for example, online refereed journals are deemed to be less credible (Shedletsky and Aitken, 2001). The prevalent notion is that anyone can create a website and place a document on the Internet for public consumption, and therefore, online scholarship is of lower quality ((Shedletsky and Aitken, 2001). Perhaps new conceptualizations of scholarship need to be examined. What are these new definitions as perceived by faculty and administrators? How do scholars ensure high standards given the rapid pace of information dissemination? How will scholarship be morphed or altered when educators become more involved in online education? Does the ancient paradigm of scholarship need to change with the changing delivery systems offered by computer technology? Questions about scholarship and research in the online environment of higher education can serve as the scaffolding for such a challenging exploration into uncharted territory. Based on the findings of this study, one outcome emerging from the data is certain: The landscape of education is dynamic and ever-evolving. It is currently infused with newness - new technological delivery systems, new concepts about learning, new roles of faculty and administrators, and new ways of teaching. How faculty and administrative leadership capitalize on these expanding opportunities will choreograph much of the future of higher education that embraces the technological revolution.

\section{References}

No Author (2004). Seven Faculty Distance Ed Trends. Academic Leader, 20(2), 7.

No Author (2000). The impact of incentive systems on faculty behaviors. Change, 32(2), 53 - 57.

Allen, E., and Seaman, J. (2003). Sizing the Opportunity: The quality and extent of online education in the United States 2002 and 2003. Sloan-C. Retrieved on April 10, 2004 from: http://www.sloan-c.org/resources/sizing_opportunity.pdf

Beaudoin, M. F. (1998). A new professoriate for the new millennium. DEOSNEWS, 8(5). Retrieved on April 12, 2004 from: http://www.ed.psu.edu/acsde/deos/deosnews/deosnews8 5.asp

Beaudoin, M. R. (1990). The instructor's changing role in distance education. The American Journal of Distance Education, 4(2), 21 - 29.

Berge, Z. L. (2002). Obstacles to distance training and education in corporate organizations. Journal of Workplace Learning, 14(5/6), $182-190$.

Brown, R. Q. (1999). Salaries and tenure of fulltime instructional faculty on 9- and 10-month contracts. U.S. Department of Education Publications, 425 - 682.

Chronicle of Higher Education (2000). Tenure and labor relations in academe. Retrieved April 12, 2005 from: http://www.chronicle.com/indepth/labor/aaup/htm

Edgerton, R. (1993). The re-examination of faculty priorities. Change, 25(4), 10 - 25.

Ellis, E. M. (2000). Faculty participation in the Pennsylvania State University World Campus: Identifying barriers to success. Open Learning, 15(3), 233 - 242.

Evans, C., and Fan, J. P. (2002). Lifelong learning through the Virtual University. Campus-Wide Information Systems, 19(4), 127 - 135. 
Folkers, D. A. (2005). Competing in the Marketplace: Incorporating online education into higher education - an organizational perspective. Information Resources Management Journal, 18(1), $61-77$.

Fredericksen, E., Pickett, A., Shea, P., Pelz, W., and Swan, K. (2000). Factors influencing faculty satisfaction with asynchronous teaching and learning in the SUNY learning network. Journal of Asynchronous Learning Networks, 4(3). Retrieved August 23, 2003 from: http://www.aln.org/publications/jaln/v4n3/index.asp

Giannoni, D. L., and Tesone, D. V. (2003). What academic administrators should know to attract senior level faculty members to online learning environments. Online Journal of Distance Learning Administration, 6(1). Retrieved April 16, 2004 from: http://www.westga.edu/ distance/ojdla/spring61/giannoni61.htm

Hartman ,J., Dziuban, C., and Moskal, P. (2000). Faculty Satisfaction in ALNs: A dependent or independent variable. Journal of Asynchronous Learning Networks, 4(3). Retrieved August 23, 2003 from: http://www.aln.org/publications/jaln/v4n3/index.asp

Jones, E. T., Lindner, J. R., Murphy, T. H., and Dooley, K. E. (2002). Faculty philosophical position towards distance education: Competency, value, and educational technology support. Online Journal of Distance Learning Administration, V, Retrieved August 23, 2003 from: http://www.westga.edu/ distance/ojdla/spring51/jones51.html

Klor de Alva, J. (2000). Remaking the academy. Educause Review, 35(2), 32 - 40.

Lataif, L. E. (1998). Lifetime tenure: A working alternative. Selections, 15, 16.

Markel, M. (1999). Distance education and the myth of the new pedagogy. Journal of Business and Technical Communication, 13(2), 208 - 222.

Moloney, M. F., Dietrick, A. S., Strickland, O., and Myerburg, S. (2003). Using Internet discussion boards as virtual focus groups. Advances in Nursing Science, 26(4), 274 - 286.

Moore, M. (1996). A System View: What is distance education? Retrieved April 12, 2004 from: http://www.cde.psu.edu/de/what_is_de.html

Olcott, D. Jr. and Wright, S. J. (1995). An institutional support framework for increasing faculty participation in postsecondary distance education. The American Journal of Distance Education 9(3), 5 - 17.

Paulson, I. (2002). Reconfiguring faculty roles for virtual settings. The Journal of Higher Education, 73(1), 123 - 140.

Redline, C. (2001). Effective Practice: Reluctant professors discover the power of Web-based tools. Educause: Effective Practices and Solutions, Retrieved August 23, 2003 from: http://www.educause.edu/ep/ep_item_detail.asp?ITEM_ID=81

Rockwell, K., Schauer, J., Fritz, S., and Marx, D. (2000). Faculty education, assistance and support needed to deliver education via distance. Journal of Distance Learning Administration, 3. Retrieved August 23, 2003 from: http://westga.edu/ distance/rockwell32.html 
Rogers, D. L. (2000). A Paradigm Shift: Technology integration for higher education in the new millennium. Educational Technology Review, 6(3), 19 - 27.

Ruch, R. S. (2001). Higher Ed. Inc.: The rise of the for-profit university. Baltimore, MD.: The John Hopkins University Press.

Ryan, M., Carlton, K. H., and Ali, N. S. (2004). Reflections on the role of faculty in distance learning and changing pedagogies. Nursing Education Perspectives, 25(2), 73 - 81.

Schneider, S. J., Kerwin, J., Frechtling, J., and Vivari, B. A. (2002). Characteristics of the discussion in online and face-to-face focus groups. Social Science Computer Review, 20(1), $31-42$.

Shedletsky, L. J., and Aitken, J. E. (2001). The paradoxes of online academic work. Communication Education, 50(3), 206 - 217.

Sloan-C-Resources (2005). Entering the maintstream: The quality and extent of online education in the United States, 2003 and 2004. Retrieved January 2, 2005 from: http://www.sloanc.org/resources/survey.asp

Sumler, D. E. (2004). Unbundling the campus. University Business, 7(1), 7 - 8.

Tierney, W. G. (1998). Tenure is dead: long live tenure. In W. G. Tierney (Ed.), The Responsible University (38-61). Baltimore, MD.: The Johns Hopkins University Press.

Vincent, A., and Ross, D. (2002). Monitoring quality of distance learning: How will accrediting agencies and universities cope? International Journal of Management Poole, 19(3), 464 471.

Wolcott, L. L. (1997). Tenure, Promotion, and Distance Education: Examining the culture of faculty rewards. The American Journal of Distance Education, 11(2), 3 - 18.

Wolcott, L. L., and Betts, K. S. (1999). What's In It for Me? Incentives for faculty participation in distance education. Journal of Distance Education, 14, 34 - 49.

\section{Endnotes}

1. Capella University is accredited by The Higher Learning Commission and a member of the North Central Association of Colleges and Schools, 30 N. LaSalle Street, Suite 2400, Chicago, IL. 60602-2504, (312) 263-0456, www.ncahigherlearningcommission.org

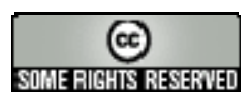

